\title{
Features, Outcomes, and Management Strategies of Male Breast Cancer: A Single Institution Comparison to Well-Matched Female Controls
}

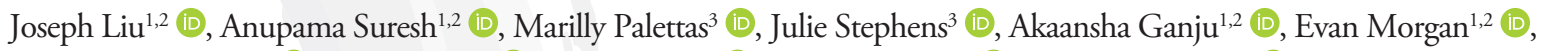

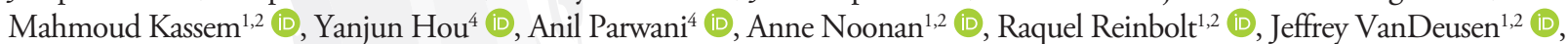

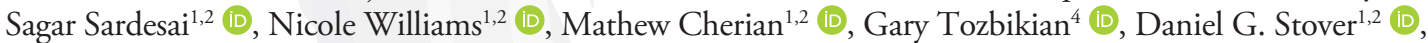 \\ Maryam Lustberg ${ }^{1,2}$ (D), Zaibo Li ${ }^{4}$ (D), Bhuvaneswari Ramaswamy ${ }^{1,2}$ (D), Robert Wesolowski ${ }^{1,2}$ (1) \\ ${ }^{1}$ Stefanie Spielman Comprehensive Breast Cancer, The Ohio State University, Columbus, OH, USA \\ ${ }^{2}$ Division of Medical Oncology, Comprehensive Cancer Center, The Ohio State University Medical Center, Columbus, OH, USA \\ ${ }^{3}$ Center for Biostatistics, Department of Biomedical Informatics, The Ohio State University, Columbus, OH, USA \\ ${ }^{4}$ Department of Pathology, The Ohio State University, Columbus, OH, USA
}

\begin{abstract}
Objective: The primary objective of this study was to delineate differences in management, overall and distant disease-free survival in males diagnosed with breast cancer and treated at The Ohio State University Comprehensive Cancer Center as compared to comprehensively matched female subjects. Secondary objectives included assessment of clinical and histopathologic features and recurrence score, as measured by Oncotype DX and the modified Magee equation \#2.

Materials and Methods: This single institution retrospective study compared male and comprehensively matched female patients (1:2) with stage I-III breast cancer between 1994 and 2014. Recurrence risk was estimated using a modified Magee equation. Overall survival and distant disease-free survival were estimated and compared using Kaplan-Meier and Log-rank methods.

Results: Forty-five male breast cancer patients were included (stage I: $26.7 \%$; stage II: 53.3\%; stage III: $20.0 \%$; hormone receptor positive: $97.8 \%$; human epidermal growth factor receptor 2 negative: $84.4 \%)$ with a median age of 63.8 (43.0-79.4) years at diagnosis. Intermediate and low recurrence scores were most common in male and female patients respectively; mean score was similar between groups (20.3 vs. 19.8). The proportion of male breast cancer patients treated with adjuvant chemotherapy and post-mastectomy radiation was lower compared to female patients ( $42.2 \%$ vs. $65.3 \%$, $\mathrm{p}=0.013 ; 22.7 \%$ vs. $44.4 \%, \mathrm{p}=0.030$, respectively). Overall survival and distant disease-free survival between male and female patients were similar.

Conclusion: Male breast cancer patient outcomes were similar compared to well-matched female patients suggesting that breast cancer specific factors are more prognostic than gender.
\end{abstract}

Keywords: Male breast cancer, matched-pair analysis, rare disease, recurrence score, survival analysis

Cite this article as: Liu J, Suresh A, Palettas M, Stephens J, Ganju A, Morgan E, et al. Features, Outcomes, and Management Strategies of Male Breast Cancer: A Single Institution Comparison to Well-Matched Female Controls. Eur J Breast Health 2020; 16(3): 201-207.

\section{Introduction}

Male breast cancer $(\mathrm{MBC})$ is a rare disease, accounting for approximately 1-2\% of all documented breast cancer cases (1). Compared to female breast cancer, MBC generally presents at an older age and later stage, with larger tumor sizes, higher nuclear grades and higher frequency of lymph node involvement $(2,3)$. Such differences may arise due to the rarity of MBC, resulting in lower patient awareness and subsequent delays in proper diagnostic workup. In addition, there is a lack of level-one evidence for the best management strategies of $\mathrm{MBC}$, as it is exceedingly difficult to accrue sufficient numbers of MBC patients to prospective clinical trials. To date, many MBC studies have been retrospective and descriptive in nature and do not have a formal comparison to female subjects. Larger studies often rely on unmatched population-level comparisons and lack detailed patient management information (4, 5). The few MBC studies that have used matched female cohorts, have often not sufficiently controlled for potential cofounding factors, such as date of diagnosis, age at diagnosis and hormone (HR) or human epidermal growth factor receptor 2 (HER2) receptors status (6-8). As such, current treatment practices for patients with $\mathrm{MBC}$ are largely based on extrapolation from clinical trials enrolling female breast cancer patients with a similar stage and histopathologic subtype.

Furthermore, in the MBC literature, it is uncertain whether prognostic genomic tests, such as Oncotype DX recurrence score (RS) (RS; Genomic Health, Redwood City, CA), can be used to help estimate prognosis and identify MBC patients who will benefit from chemotherapy, given that these scores are based on studies performed in female breast cancer patients (9-11). Limited data exists on the utility of 
Oncotype DX for MBC (12-15). As a result, there have been greater strides for women in breast cancer detection, incidence, and mortality compared to men $(1,2)$.

The main objective of this study was to compare clinical characteristics, treatment practices and outcomes between male and comprehensively matched female patients with breast cancer treated at a single institution, The Ohio State University Comprehensive Cancer Center (OSUCCC). We also obtained the results of Oncotype DX in male and female cohorts, when available, and calculated RS based on modified Magee scores (University of Pittsburgh Medical Center (UPMC) Magee-Women's Hospital), a less expensive and well-validated alternative that estimates RS based on several pathological variables and semiquantitative immunohistochemical results $(16,17)$.

\section{Materials and Methods}

\section{Study design}

This study was a retrospective chart review of clinical and histopathologic data from breast cancer patients seen at the OSUCCC between 1994 and 2014.

Ethical Committee: The study was approved by the Ohio State University Cancer Institutional Review Board (OSU IRB 2015C0153).

Informed Consent: Due to the retrospective nature of the study, a full waiver of the informed consent process was obtained from the Ohio State University Cancer Institutional Review Board.

Eligibility: Eligible patients were identified by ICD-9 code (174.0174.9) and included MBC patients who received treatment at this institution. Patients with incomplete clinical data and those treated at other institutions were excluded. The MBC cohort was comprehensively matched in a 1:2 ratio to a female cohort (see "Statistical Methods" below for details).

\section{Data collection}

Data were initially queried and obtained from The Ohio State University Information Warehouse and uploaded into Research Electronic Data Capture (REDCap) (18). Data missing from the initial query were populated using manual review of each patient's electronic medical record. The following data were extracted from patients' records: demographic information, stage at diagnosis (based on the American Joint Committee on Cancer (AJCC) $7^{\text {th }}$ edition), tumor grade, estrogen receptor (ER) and progesterone receptor (PR) and HER2 status, Oncotype DX RS, location and date of distant metastases, locoregional and systemic management information, date of death and last known follow-up.

\section{Outcomes measures}

The primary objective of this study was to delineate differences in management, overall and distant disease-free survival in males diagnosed with breast cancer and treated at the OSUCCC as compared

\section{Key Points}

- Well matched study between male and female breast cancer with regard to clinical features, management and outcomes.

- Assessment of overall survival and distant disease free survival in both cohorts.

- Description of differences in treatment modalities in both male and female breast cancer cohorts. to comprehensively matched female subjects. Secondary objectives included assessment of clinical and histopathologic features and the RS, as measured by Oncotype DX and the modified Magee equation \#2. Oncotype DX is a commonly used 21-gene reverse transcription, polymerase chain reaction assay performed on breast tumor tissue that estimates the 10-year risk of recurrence and predicts benefit from chemotherapy (the details have been extensively described previously) (11). The modified Magee equation \#2 incorporates tumor grade (based on Nottingham Score), ER and PR expression (based on H-Score), HER2 amplification, and tumor size to give a validated estimate of Oncotype DX RS $(16,19)$. The equation was derived from a linear regression analysis of a large single-institution patient cohort $(\mathrm{n}=800)$. RSs are reported on a scale of $0-100$ and used to be categorized into low $(<18)$, intermediate (18-30) and high (>30) (11). More recently, a large prospective study demonstrated that RS of $\leq 25$ and $\leq 15$ were associated with excellent prognosis and lack or benefit from adjuvant chemotherapy in women aged $>50$ years and $\leq 50$ years respectively (20).

\section{Statistical analysis}

The MBC cohort included 45 men diagnosed with non-metastatic breast cancer from 1994-2014. The female cohort included randomly selected female breast cancer patients that were matched at a maleto-female ratio of 1:2 (if matched female breast cancer patients were available) on the following criteria: age of diagnosis, year of diagnosis (both within 5 years), stage at diagnosis, ER, PR, and HER2 status. Matching was done using variable optimal matching (vmatch macro) (21). Two female matches were identified for 34 males, one female match for seven males and there were no matches found for four male patients.

Demographic and clinical characteristics as well as treatment modalities were summarized for the two cohorts using descriptive statistics. Comparisons between males and females included treatment management for patients, clinical characteristics of patients (see Data Collection section), and RS. Categorical variables were compared between males and females using either a Chi-square test/Fisher's Exact test, and continuous variables were compared with a two sample t-test/ Wilcoxon Rank Sum test. Overall survival (OS) was defined as the time from date of diagnosis to date of death, and distant disease-free survival (DDFS) was defined as the time from date of diagnosis to first metastases or death. Patients were censored at the date last known to be alive. OS and DDFS estimates were generated by sex using Kaplan Meier methods and were compared between sexes using Log-rank tests. All data analyses were performed using suite of analytics software (SAS) 9.4 (SAS Institute Inc., Cary, NC, USA) or Stata 14 (StataCorp LLC, College Station, TX, USA).

\section{Results}

\section{Patient characteristics}

A total of 45 male patients and 75 matched female patients were included in this study. A summary of demographic and clinical characteristics is displayed in Table 1 . Both males and females were predominately white $(77.8 \%$ and $85.3 \%$, respectively). The median age at diagnosis for males and females was 63.8 years and 63.1 years, respectively, and the median body mass index at diagnosis was 31.0 and 29.9, respectively. Male patients were predominantly HR positive and HER2 negative (97.8\% were ER and/or PR positive; 8.9\% HER2+; $6.7 \%$ HER2 unknown; $2.3 \%$ Triple Negative) and the majority were stage II at the time of diagnosis (stage I: $26.7 \%$; stage II: $53.3 \%$; stage III: $20.0 \%$ ). The proportion of patients with pathologically positive 
lymph nodes was lower in males than females $(46.7 \%$ and $57.3 \%$, $\mathrm{p}=0.225$, respectively). Male patients also had a higher proportion of intermediate and high-grade tumors compared to female patients (Low: $13.3 \%$ vs. $30.7 \%$; Intermediate: $64.4 \%$ vs. $46.7 \%$; High: $22.2 \%$ vs $18.7 \%$, respectively). In patients who experienced distant recurrence ( $\mathrm{n}=45$ for males and $\mathrm{n}=75$ for females), bone, brain, and liver metastases were more common in women, whereas lung metastases were more common in men (Table 2).

\section{Table 1. Demographic and clinical characteristics of} male and female breast cancer patients

\begin{tabular}{|c|c|c|}
\hline Characteristics & $\begin{array}{c}\text { Males } \\
(n=45) \\
\text { No. (\%) }\end{array}$ & $\begin{array}{c}\text { Females } \\
(n=75) \\
\text { No. }(\%)\end{array}$ \\
\hline $\begin{array}{l}\text { Age at diagnosis, } \\
\text { median (range) }\end{array}$ & $63.8(43.0-79.4)$ & $63.1(42.0-79.0)$ \\
\hline $\begin{array}{l}\text { BMI at diagnosis, } \\
\text { median (range) }\end{array}$ & $31.0(20.0-45.5)$ & $29.9(16.1-48.5)$ \\
\hline \multicolumn{3}{|l|}{ Race } \\
\hline White & $35(77.8)$ & $64(85.3)$ \\
\hline Black & $7(15.6)$ & $9(12.0)$ \\
\hline Other & $3(6.7)$ & $2(2.7)$ \\
\hline \multicolumn{3}{|l|}{ Stage } \\
\hline 1 & $12(26.7)$ & $21(28.0)$ \\
\hline 2 & $24(53.3)$ & $37(49.3)$ \\
\hline 3 & $9(20.0)$ & $17(22.7)$ \\
\hline \multicolumn{3}{|l|}{ Grade } \\
\hline 1 & $6(13.3)$ & $23(30.7)$ \\
\hline 2 & $29(64.4)$ & $35(46.7)$ \\
\hline 3 & $10(22.2)$ & $14(18.7)$ \\
\hline Unknown & $0(0.0)$ & $3(4.0)$ \\
\hline \multicolumn{3}{|c|}{ Lymph node status } \\
\hline Positive & $21(46.7)$ & $43(57.3)$ \\
\hline Negative & $24(53.3)$ & $31(41.3)$ \\
\hline Unknown & $0(0.0)$ & $1(1.3)$ \\
\hline \multicolumn{3}{|l|}{ ER status } \\
\hline Positive & $44(97.8)$ & $73(97.3)$ \\
\hline Negative & $1(2.2)$ & $2(2.7)$ \\
\hline \multicolumn{3}{|l|}{ PR status } \\
\hline Positive & $38(84.4)$ & $64(85.3)$ \\
\hline Negative & $5(11.1)$ & $11(14.7)$ \\
\hline Unknown & $2(4.4)$ & $0(0.0)$ \\
\hline \multicolumn{3}{|l|}{ HER2 status } \\
\hline Positive & $4(8.9)$ & $5(6.7)$ \\
\hline Negative & $38(84.4)$ & 70 (93.3) \\
\hline Unknown & $3(6.7)$ & $0(0.0)$ \\
\hline
\end{tabular}

BMI: body mass index; ER: estrogen receptor; PR: progesterone receptor; HER2: human epidermal growth factor receptor; SD: standard deviation

\section{Treatment modalities}

Table 3 summarizes treatment management of the study cohorts. There were several differences in the management observed between the male and female cohorts. As expected, use of breast-conserving surgery differed significantly, with male patients undergoing mastectomies more frequently than female patients $(97.8 \%$ vs. $60.0 \%, \mathrm{p}<0.001)$. No male patients had breast-conserving surgery, compared to 27 female patients $(36.0 \%)$. Of the patients who underwent a mastectomy, fewer males were treated with radiotherapy compared to matched female patients $(22.7 \%$ vs. $44.4 \%$; $\mathrm{p}=0.030)$. In addition, a lower percentage of males received chemotherapy compared to females ( $42.2 \%$ vs. $65.3 \%$; $\mathrm{p}=0.013$ ), with similar proportions receiving anthracycline-containing chemotherapy ( $33.3 \%$ vs. $46.7 \%$; $\mathrm{p}=0.152)$. However, these observa-

Table 2. Clinical summary of male and female patients with metastatic disease

\begin{tabular}{lcc} 
& $\begin{array}{c}\text { Males } \\
(\mathbf{n = 4 5 )} \\
\text { No. }(\%)\end{array}$ & $\begin{array}{c}\text { Females } \\
(\mathbf{n = 7 5 )} \\
\text { No. }(\%)\end{array}$ \\
\hline $\begin{array}{l}\text { Site of metastases } \\
\text { Bone }\end{array}$ & $3(6.7)$ & $14(18.7)$ \\
Brain & $0(0.0)$ & $3(4.0)$ \\
Liver & $2(4.4)$ & $8(10.7)$ \\
Lung & $3(6.7)$ & $3(4.0)$ \\
Other & $0(0.0)$ & $3(4.0)$
\end{tabular}

Table 3. Summary of treatment management of male and female breast cancer patients

\begin{tabular}{|c|c|c|c|}
\hline Treatment & $\begin{array}{c}\text { Males } \\
(\mathrm{n}=45) \\
\text { No. (\%) }\end{array}$ & $\begin{array}{c}\text { Females } \\
(n=75) \\
\text { No. (\%) }\end{array}$ & $\mathbf{p}$ \\
\hline \multicolumn{4}{|l|}{ Surgery } \\
\hline Complete mastectomy & $44(97.8)$ & $45(60.0)$ & \\
\hline Lumpectomy & $0(0.0)$ & $27(36.0)$ & $<0.0001$ \\
\hline None & $1(2.2)$ & $3(4.0)$ & \\
\hline Radiotherapy & $11(24.4)$ & $47(62.7)$ & $<0.0001$ \\
\hline Post-mastectomy & $10(22.7)$ & $20(44.4)$ & 0.0302 \\
\hline Chemotherapy & $19(42.2)$ & $49(65.3)$ & 0.0134 \\
\hline Anthracyclines & $15(33.3)$ & $35(46.7)$ & 0.1515 \\
\hline Endocrine therapy & $41(91.1)$ & $69(92.0)$ & 1.0000 \\
\hline Tamoxifen & $38(84.4)$ & $19(25.3)$ & $<0.0001$ \\
\hline Al & $10(22.2)$ & $64(85.3)$ & $<0.0001$ \\
\hline SERD & $1(2.2)$ & $4(5.3)$ & 0.6492 \\
\hline $\mathrm{GnRH}$ agonists & $4(8.9)$ & $3(4.0)$ & 0.4228 \\
\hline $\begin{array}{l}\text { Median (range) } \\
\text { duration, months }\end{array}$ & $\begin{array}{c}59.7 \\
(7.7-186.1)^{\mathrm{a}}\end{array}$ & $\begin{array}{c}59.5 \\
(0.4-122.3)^{\mathrm{b}}\end{array}$ & 0.8141 \\
\hline
\end{tabular}

Al: aromatase inhibitor; GnRH: gonadotropin releasing hormone; SD: standard deviation; SERD: selective estrogen receptor degrader. ${ }^{a} \mathrm{n}=40$; ${ }^{\mathrm{b}} \mathrm{n}=69$ 
tions may be the result of lower proportion of MBC patients with node positive disease, thus not meeting standard criteria for post-mastectomy radiation and adjuvant chemotherapy.

There was no significant difference in the proportion of endocrine therapy use between male and female patients ( $91.1 \%$ vs. $92.0 \%, \mathrm{p}=0.999)$. Compared to females, the majority of male patients received tamoxifen ( $84.4 \%$ vs. $25.3 \%, \mathrm{p}<0.001)$, whereas most female patients received an aromatase inhibitor (AI) $(85.3 \%$ vs. $22.2 \%, \mathrm{p}<0.001)$. Crossover between tamoxifen and AI therapy occurred in 8 female patients. There was no difference in median duration of adjuvant hormonal therapy between male and female patients (59.7 months vs. 59.5 months, $\mathrm{p}=0.814$ ). Adherence to endocrine therapy was similar between the 2 groups with $72.5 \% \mathrm{MBC}$ patients completing at least 48 months of tamoxifen compared to $63.8 \%$ of matched female breast cancer $(\mathrm{p}=0.350)$.

\section{Survival}

Survival results are summarized in Table 4 and Figure 1 and 2. No difference in the Kaplan-Meier curves was found between males and females in OS or DDFS (OS: $p=0.287$; DDFS: $p=0.318$; Figure 1). Among patients receiving chemotherapy, marginal differences were detected in OS and DDFS between males and females favoring male patients ( $\mathrm{p}=0.054$ for OS; $\mathrm{p}=0.045$ for DDFS; Figure $2 \mathrm{a}$ and $\mathrm{b}$ ) and no differences were detected in OS or DDFS between males and females treated without chemotherapy $(\mathrm{p}=0.172 ; \mathrm{p}=0.102$; Figure $2 \mathrm{c}$ and $\mathrm{d})$.

\section{Table 4. Survival analysis of male and female breast cancer patients}

\begin{tabular}{|c|c|c|c|}
\hline Treatment & $\begin{array}{c}\text { Males } \\
(n=45) \\
\text { No. (\%) }\end{array}$ & $\begin{array}{c}\text { Females } \\
(n=74) \\
\text { No. }(\%)\end{array}$ & $\mathbf{p}$ \\
\hline \multicolumn{4}{|l|}{ Overall Survival } \\
\hline Death & $8(17.8)$ & $16(21.6)$ & 0.287 \\
\hline Median TTD, years & $\mathrm{N} / \mathrm{A}$ & 12.9 & \\
\hline \multicolumn{4}{|c|}{ Distant Disease-Free Survival } \\
\hline Disease progression & $9(20.0)$ & $18(24.3)$ & 0.318 \\
\hline Median TTP, years & $\mathrm{N} / \mathrm{A}$ & 11.1 & \\
\hline
\end{tabular}

Table 5. Recurrence risk calculation using Oncotype DX and the modified Magee equation

\begin{tabular}{|cccc} 
& Males & Females & p \\
\hline Oncotype DX & $\mathrm{n}=5$ & $\mathrm{n}=12$ & \\
RS; mean (SD) & $18.8(5.7)$ & $13.7(9.4)$ & 0.2777 \\
Range & $11-26$ & $0-33$ & \\
Modified Magee & $\mathrm{n}=26$ & $\mathrm{n}=47$ & \\
RS; mean (SD) & $20.3(6.3)$ & $19.8(8.1)$ & 0.8222 \\
Low; $\mathrm{n}(\%)$ & $9(34.6)$ & $23(48.9)$ & \\
Intermediate; $\mathrm{n}(\%)$ & $16(61.5)$ & $18(38.3)$ & 0.1620 \\
High; $\mathrm{n}(\%)$ & $1(3.9)$ & $6(12.8)$ & \\
\hline
\end{tabular}

\section{Oncotype DX and modified Magee recurrence scores}

Table 5 provides the summary of Oncotype DX and Magee scores in the study cohorts. Oncotype DX RSs were available for 5 men $(11.1 \%)$ and 12 women $(16.0 \%)$. Due to the low number of Oncotype DX testing performed, the modified Magee equation was used to estimate recurrence risk. The modified Magee recurrence scores could be calculated for 26 men $(57.8 \%)$ and 47 women (62.7\%). Mean scores were similar between male and female cohorts (20.3, range 7.5-31.2, SD 6.3 vs. 19.8 , range $8.8-39.4$, SD $8.1 ; \mathrm{p}=0.822$ ). There was also no statistically significant difference in the categorized Magee score distribution between males and females, although, the intermediate score was most common in male subjects, while the low score was most common in female subjects (Low: 34.6\%; Intermediate: 61.5\%; High: $3.9 \%$ for males and Low: $48.9 \%$; Intermediate: $38.3 \%$; High: $12.8 \%$ for females, $\mathrm{p}=0.162$ ).

\section{Discussion and Conclusion}

This single institution, retrospective study compared clinical and histopathologic features, management, and outcomes between patients with stage I-III MBC and a well-matched female breast cancer cohort. As expected, MBC patients in our study primarily presented with a higher rate of HR-positivity (97.8\%) and a lower rate of HER2 amplification $(8.9 \%)$ compared to historical female breast cancer data (approximately 75\% HR+; 18-25\% HER2+) (6, 22, 23). Results sug-
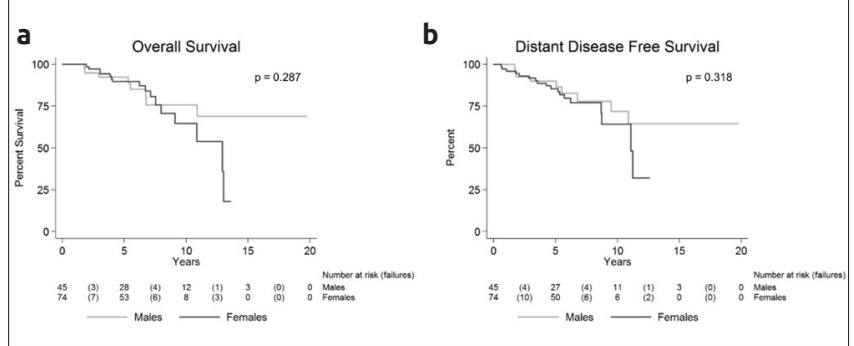

Figure 1. a, b. Survival estimates in male and female study subjects. (a) Overall survival. (b) Distant disease-free survival

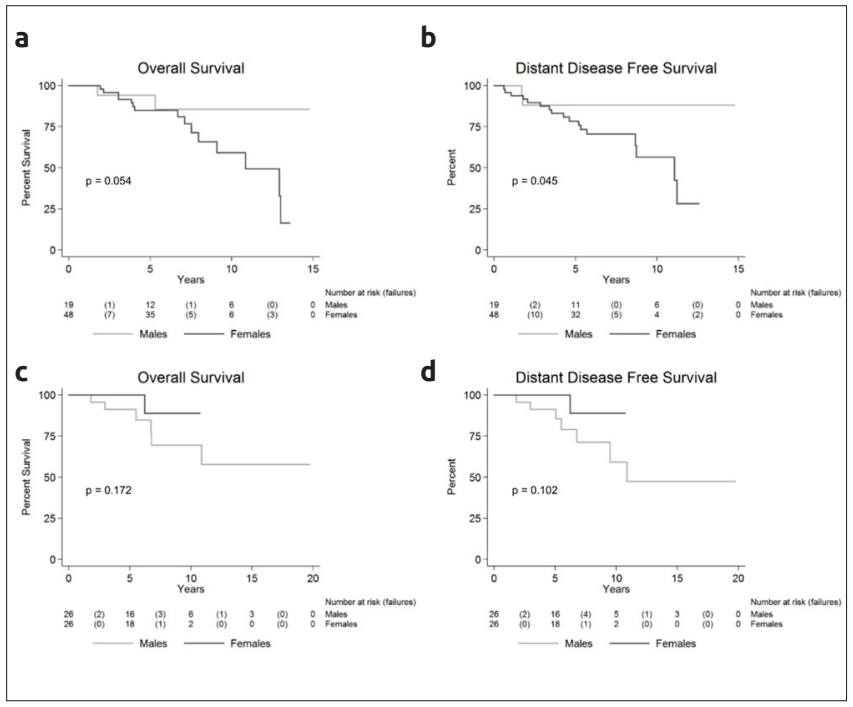

Figure 2. a-d. Overall and distant disease-free survival between male and female patients based on receipt of chemotherapy. (a) Overall survival in patients treated with chemotherapy. (b) Distant diseasefree survival in patients treated with chemotherapy. (c) Overall survival of patients not treated with chemotherapy. (d) Distant disease-free survival of patients not treated with chemotherapy 
gested no overall differences in OS or DDFS, but there were important differences in the management of cancer between the two cohorts. For instance, while the use of hormone therapy overall did not differ between the male and female cohorts (as expected tamoxifen was used much more frequently in male subjects) the rate of breast conserving surgery and adjuvant chemotherapy was significantly lower in male patient compared to well match female subjects.

Use of tamoxifen as adjuvant endocrine therapy for $\mathrm{MBC}$ is in line with contemporary best practices as evidenced by a strong preference for tamoxifen use over AIs in most previously published reports $(2,7$, 24). The median duration of endocrine therapy was similar between $\mathrm{MBC}$ and female breast cancer patients and approached the 5-year standard of care at the time. Furthermore, $72.5 \% \mathrm{MBC}$ patients in our study completed at least 48 months of tamoxifen compared to $63.8 \%$ of matched female breast cancer ( $\mathrm{p}=0.350)$. Tamoxifen adherence (defined as $\geq 80 \%$ ) in female breast cancer is associated with improved OS (25). Local treatment for breast cancer differed between the two cohorts, with every male patient in this study who had breast surgery for operable cancer undergoing a mastectomy, a finding comparable to existing literature $(24,26)$. There are several explanations for this finding, including the scarcity of breast tissue and tendency for men to present with more advanced disease, including larger tumor size and higher rates of chest wall and retro-areolar infiltration (27). Furthermore, the results show that the proportion of males on adjuvant radiotherapy after mastectomy was much lower compared to females. Existing literature has reported anywhere between 3-100\% of male patients received adjuvant radiotherapy and are largely heterogeneous in their conclusions, some of which are artifacts of high prevalence of advanced disease with axillary nodal involvement (28-33). The lower proportion of lymph node positivity in male patients relative to female patients in our study may confound our observations. There was no significant difference in OS or DDFS between male and female cohorts in this study. Previous retrospective studies also found no difference in OS or progression-free survival in $\mathrm{MBC}$ compared to female breast cancer when matched by age and stage (3, 4, 34, 35). Therefore, long-term outcomes of male patients may not be significantly different from female patients when matched for stage, HR and HER2 status, age of diagnosis, and other prognostic factors, despite significant differences in management.

Since most prognostic tests are based on female study populations and do not account for sex-based genomic or molecular disparities, differences in RS as determined by Oncotype DX for male and female breast cancer are an important area of active research $(13,36,37)$. A recent study of 322 men demonstrated that MBC patients are dissimilar in terms of prognostic information contained within the Oncotype DX RS results. Among breast cancer patients with high RSs ( $R S \geq 31$ ), the 5-year breast cancer-specific survival was significantly lower for MBC than female patients (12). In order to address RS discrepancies between the male and female breast cancer patients, we assessed RSs with a modified Magee equation (16). We found that overall, modified Magee scores were similar between male and female cohorts. However, male patients more commonly had intermediate RSs, while matched female patients more commonly had low RSs. These minor differences may be attributed to variation in tumor biology as measured by the unmatched Magee score parameters, namely $\mathrm{H}$-score and tumor grade. Unfortunately, due to a small sample size, we were unable to compare DDFS and OS between low, intermediate and high Magee recurrence scores. Interestingly, there was discrepancy in chemotherapy use based on RS as calculated by Magee equation with higher proportion of fe- male breast cancer patients treated with adjuvant chemotherapy across all RS categories. Within the low RS group, 22\% of MBC patients ( 2 out of 9 ) and $35 \%$ female patients ( 8 of 23 ) had chemotherapy. In the intermediate category, $50 \%$ of males and $83 \%$ of female patients had chemotherapy. The high RS group had no MBC patient who had chemotherapy, while 5 out of 6 female patients (83\%) had adjuvant chemotherapy.

We feel that the biggest strength of present study is the use of a cohort of female breast cancer patients that were well-matched to the male patients: the majority of male patients were matched with two females based on age of diagnosis (within five years), year of diagnosis (within five years), stage at diagnosis, ER, PR, and HER2 status. There are, however, some limitations of this analysis that are worth noting. The study spans a large time frame, during which standard therapies for breast cancer have changed. However, we attempted to minimize the effect of the diagnosis date by matching patients that were diagnosed within 5 years of each other. Despite this comprehensive matching used in this study, less stage IIA MBC patients had node positive disease than stage IIA female patients, which could explain imbalances in the proportion of patients receiving post-mastectomy radiation and adjuvant chemotherapy. In addition, although a broad time frame was used to capture cases, the number of male cases was relatively small which prevented analysis of the association between survival and RSs and limits the generalizability of the survival analysis. Furthermore, the paucity of histopathological data in certain patients limited our use of the modified Magee equation and resulted in about $45 \%$ of cases missing RSs.

In conclusion, the rarity of $\mathrm{MBC}$ makes it very challenging to study this population in either randomized clinical trials or cohort studies. Aside from the International Male Breast Cancer Program of the European Organization for Research and Treatment of Cancer (EORTC), this study is one of the largest matched cohort studies to date. Results highlight that there is no significant difference in overall or distant disease-free survival, despite some differences in management of the disease between male and well-matched female breast cancer patients. This suggests that breast cancer specific factors rather than gender play a role in patient outcome and early detection and appropriate treatment are critical factors affecting survival of male patients with breast cancer.

Ethics Committee Approval: Ethics committee approval was received for this study from the ethics committee of Ohio State University Cancer Institutional Review Board (OSU IRB 2015C0153).

Informed Consent: Due to the retrospective nature of the study, a full waiver of the informed consent process was obtained from the Ohio State University Cancer Institutional Review Board.

Peer-review: Externally peer-reviewed.

Author Contributions: Concept - R.W., B.R.; Design - J.L.; Supervision R.W., B.R.; Resources - R.W.; Materials - J.L., M.P., J.S.; Data Collection and/ or Processing - J.L., A.S., A.G., E.M., M.K.; Analysis and/or Interpretation J.S., M.P., J.L., E.M., M.K.; Literature Search - J.L., A.S., A.G., E.M., M.K.; Writing Manuscript - J.L., A.S., M.P., J.S., A.G., E.M., M.K., Y.H., A.P., A.N., R.R., J.vD., S.S., N.W., M.C., G.T., D.G.S., M.L., Z.L., B.R., R.W.; Critical Review - Y.H., A.P., A.N., R.R., H.V., S.S., N.W., M.C., G.T., D.S., M.L., Z.L., B.R., R.W. 
Acknowledgements: The project described was supported by the Stefanie Spielman Fund for Breast Cancer Research. Additional support was provided by the National Center for Advancing Translational Sciences [grant number UL1TR002733]. The content is solely the responsibility of the authors and does not necessarily represent the official views of the National Center for Advancing Translational Sciences or the National Institutes of Health.

Conflict of Interest: The authors have no conflicts of interest to declare.

Financial Disclosure: The authors declared that this study has received no financial support.

\section{References}

1. Surveillance E. End Results (SEER) Program Research Data (1973-2015), (www.seer.cancer.gov). 2018.

2. Anderson WF, Jatoi I, Tse J, Rosenberg PS. Male breast cancer: a population-based comparison with female breast cancer. JCO 2010; 28: $232-$ 239. (PMID:19996029) [CrossRef]

3. Giordano SH, Cohen DS, Buzdar AU, Perkins G, Hortobagyi GN. Breast carcinoma in men: a population囚based study. Cancer 2004; 101: 51-57. (PMID:15221988) [CrossRef]

4. Bradley KL, Tyldesley S, Speers CH, Woods R, Villa D. Contemporary systemic therapy for male breast cancer. Clin Breast Cancer 2014; 14: 3139. (PMID:24220158) [CrossRef]

5. Leone JP, Leone J, Zwenger AO, Iturbe J, Vallejo CT, Leone BA. Prognostic significance of tumor subtypes in male breast cancer: a population-based study. Breast Cancer Res Treat 2015; 152: 601-609. (PMID: 26126972) [CrossRef]

6. Scott-Conner CE, Jochimsen PR, Menck HR, Winchester DJ. An analysis of male and female breast cancer treatment and survival among demographically identical pairs of patients. Surgery 1999; 126: 775-781. (PMID:10520928) [CrossRef]

7. Eggemann H, Altmann U, Costa SD, Ignatov A. Survival benefit of tamoxifen and aromatase inhibitor in male and female breast cancer. J Cancer Res Clin Oncol 2018; 144: 337-341. (PMID:29098396) [CrossRef]

8. Cui Q, Kong D, Li Z, Ahiable P, Wang K, Wu K, Wu G. Dachshund 1 is differentially expressed between male and female breast cancer: a matched case-control study of clinical characteristics and prognosis. Clin Breast Cancer 2018; 18: e875-882. (PMID:29478945) [CrossRef]

9. Paik S, Tang G, Shak S, Kim C, Baker J, Kim W, Cronin M, Baehner FL, Watson D, Bryant J, Costantino JP, Geyer Jr CE, Wickerham DL, Wolmark N. Gene expression and benefit of chemotherapy in women with node-negative, estrogen receptor-positive breast cancer. J Clin Oncol 2006; 24: 3726-3734. (PMID:16720680) [CrossRef]

10. Nguyen MT, Stessin A, Nagar H, D’Alfonso TM, Chen Z, Cigler T, Hayes MK, Shin SJ. Impact of oncotype DX recurrence score in the management of breast cancer cases. Clin Breast Cancer 2014; 14: 182190. (PMID:24486121) [CrossRef]

11. Paik S, Shak S, Tang G, Kim C, Baker J, Cronin M, Baehner FL, Walker MG, Watson D, Park T, Hiller W, Fisher ER, Wickerham DL, Bryant J, Wolmark N. A multigene assay to predict recurrence of tamoxifen-treated, node-negative breast cancer. N Engl J Med 2004; 351: 2817-2826. (PMID:15591335) [CrossRef]

12. Massarweh SA, Sledge GW, Miller DP, McCullough D, Petkov VI, Shak $\mathrm{S}$. Molecular characterization and mortality from breast cancer in men. J Clin Oncol 2018; 36: 1396. (PMID:29584547). [CrossRef]

13. Shak S, Palmer G, Baehner FL, Millward C, Watson D, Sledge Jr GW. Molecular characterization of male breast cancer by standardized quantitative RT-PCR analysis: first large genomic study of 347 male breast cancers compared to 82,434 female breast cancers. J Clin Oncol 2009; 27: 549.

14. Rayson D, Erlichman C, Suman VJ, Roche PC, Wold LE, Ingle JN, Donohue JH. Molecular markers in male breast carcinoma. Cancer 1998; 83: 1947-1955. (PMID: 9806653). [CrossRef]
15. Piscuoglio S, Ng CK, Murray MP, Guerini-Rocco E, Martelotto LG, Geyer FC, Bidard FC, Berman S, Fusco N, Sakr RA, Eberle CA, De Mattos-Arruda L, Macedo GS, Akram M, Baslan T, Hicks JB, King TA, Brogi E, Norton L, Weigelt B, Hudis CA, Reis-Filho JS. The genomic landscape of male breast cancers. Clin Cancer Res 2016; 22: 4045-4056. (PMID: 26960396) [CrossRef]

16. Klein ME, Dabbs DJ, Shuai Y, Brufsky AM, Jankowitz R, Puhalla SL, Bhargava R. Prediction of the Oncotype DX recurrence score: use of pathology-generated equations derived by linear regression analysis. Mod Pathol 2013; 26: 658-664. (PMID: 23503643) [CrossRef]

17. Equations M. Available at: http://path.upmc.edu/onlineTools/mageeequations.html. 2018.

18. Harris PA, Taylor R, Thielke R, Payne J, Gonzalez N, Conde JG. Research electronic data capture (REDCap)-a metadata-driven methodology and workflow process for providing translational research informatics support. J Biomed Inform 2009; 42: 377-381. (PMID: 18929686) [CrossRef]

19. Flanagan MB, Dabbs DJ, Brufsky AM, Beriwal S, Bhargava R. Histopathologic variables predict Onco type $\mathrm{DX}^{\mathrm{m}}$ Recurrence Score. Mod Pathol 2008; 21: 1255-1261. (PMID: 18360352) [CrossRef]

20. Sparano JA, Gray RJ, Makower DF, Pritchard KI, Albain KS, Hayes DF, Geyer Jr CE, Dees EC, Goetz MP, Olson Jr JA, Lively T, Badve SS, Saphner TJ, Wagner LI, Whelan TJ, Ellis MJ, Paik S, Wood WC, Ravdin PM, Keane MM, Moreno HLG, Reddy PS, Goggins TF, Mayer IA, Brufsky AM, Toppmeyer DL, Kaklamani VG, Berenberg JL, Abrams JA, Sledge Jr GW. Adjuvant chemotherapy guided by a 21-gene expression assay in breast cancer. N Engl J Med 2018; 379: 111-121. (PMID: 29860917)

21. Division of Biomedical Statistics and Informatics - Locally Written SAS Macros. Mayo Clinic Available at: http://www.mayo.edu/research/departments-divisions/department-health-sciences-research/division-biomedical-statistics-informatics/software/locally-written-sas-macros. (Accessed: 8th June 2018).

22. Anderson WF, Chatterjee N, Ershler WB, Brawley OW. Estrogen receptor breast cancer phenotypes in the Surveillance, Epidemiology, and End Results database. Breast Cancer Res Treat 2002; 76: 27-36. (PMID: 12408373) [CrossRef]

23. Slamon DJ, Godolphin W, Jones LA, Holt JA, Wong SG, Keith DE, Levin WJ, Stuart SG, Udove J, Ullrich A. Studies of the HER-2/neu proto-oncogene in human breast and ovarian cancer. Science 1989; 244 : 707-712. (PMID: 2470152) [CrossRef]

24. Cutuli B, Le-Nir CC, Serin D, Kirova Y, Gaci Z, Lemanski C, De Lafontan B, Zoubir M, Maingon P, Mignotte H, Tunon de Lara C, Edeline J, Penault-Llorca F, Romestaing P, Delva C, Comet B, Belkacemi Y. Male breast cancer. Evolution of treatment and prognostic factors. Analysis of 489 cases. Crit Rev Oncol Hematol 2010; 73: 246-254. (PMID: 19442535) [CrossRef]

25. McCowan C, Shearer J, Donnan PT, Dewar JA, Crilly M, Thompson AM, Fahey TP. Cohort study examining tamoxifen adherence and its relationship to mortality in women with breast cancer. Br J Cancer 2008; 99 : 1763-1768. (PMID: 18985046) [CrossRef]

26. Fogh S, Kachnic LA, Goldberg SI, Taghian AG, Powell SN, Hirsch AE. Localized therapy for male breast cancer: functional advantages with comparable outcomes using breast conservation. Clin Breast Cancer 2013; 13: 344-349. (PMID: 23891587) [CrossRef]

27. Patten DK, Sharifi LK, Fazel M. New approaches in the management of male breast cancer. Clin Breast Cancer 2013; 13: 309-314. (PMID: 23845572) [CrossRef]

28. Cutuli B, Lacroze M, Dilhuydy JM, Veiten M, De Lafontan B, Marchal C, Resbeut M, Graic Y, Campana F, Moncho-Bernier V. Male breast cancer: results of the treatments and prognostic factors in 397 cases. Eur J Cancer 1995; 31: 1960-1964. (PMID: 8562148) [CrossRef]

29. Chakravarthy A, Kim CR. Post-mastectomy radiation in male breast cancer. Radiother Oncol. 2002; 65: 99-103. (PMID: 12443805) [CrossRef]

30. Borgen PI, Wong GY, Vlamis VA, Potter CH, Hoffmann BR, Kinne DW, Osborne MP, McKinnon WM. Current management of male breast cancer. A review of 104 cases. Ann Surg 1992; 215: 451-9. (PMID: 1319699) [CrossRef] 
31. Stierer M, Rosen H, Weitensfelder W, Hausmaninger H, Teleky B, Jakesz R, Fruhwirth H, Dünser M, Beller S, Haid A. Male breast cancer: Austrian experience. World J Surg 1995; 19: 687-692. (PMID: 7571664) [CrossRef]

32. Stranzl H, Mayer R, Quehenberger F, Prettenhofer U, Willfurth P, Stöger $\mathrm{H}, \mathrm{Hackl} \mathrm{A}$. Adjuvant radiotherapy in male breast cancer. Radiother Oncol 1999; 53: 29-35. (PMID: 10624850) [CrossRef]

33. Hultborn R, Friberg S, Hultborn KA, Peterson LE, Ragnhult I. Male Breast Carcinoma: II. A study of the total material reported to the Swedish Cancer Registry 1958--1967 with respect to treatment, prognostic factors and survival. Acta Oncol 1987; 26: 327-341. (PMID: 3322330) [CrossRef]

34. Korde LA, Zujewski JA, Kamin L, Giordano S, Domchek S, Anderson WF, Bartlett JMS, Gelmon K, Nahleh Z, Bergh J, Cutuli B, Pruneri
G, McCaskill-Stevens W, Gralow J, Hortobagyi G, Cardoso F. Multidisciplinary meeting on male breast cancer: summary and research recommendations. J Clin Oncol 2010; 28: 2114-2122. (PMID: 20308661) [CrossRef]

35. Ribeiro GG, Swindell R, Harris M, Banerjee SS, Cramer A. A review of the management of the male breast carcinoma based on an analysis of 420 treated cases. Breast 1996; 5: 141-146. [CrossRef]

36. Grenader T, Yerushalmi R, Tokar M, Fried G, Kaufman B, Peretz T, Geffen DB. The 21-gene recurrence score assay $\left(\right.$ Oncotype $\left.\mathrm{DX}^{\mathrm{rm}}\right)$ in estrogen receptor-positive male breast cancer: experience in an Israeli cohort. Oncology 2014; 87: 1-6. (PMID: 24970679) [CrossRef]

37. Turashvili G, Gonzalez-Loperena M, Brogi E, Dickler M, Norton L, Morrow M, Wen HY. The 21-gene recurrence score in male breast cancer. Ann Surg Oncol 2018; 25: 1530-1535. (PMID: 29520654) [CrossRef] 